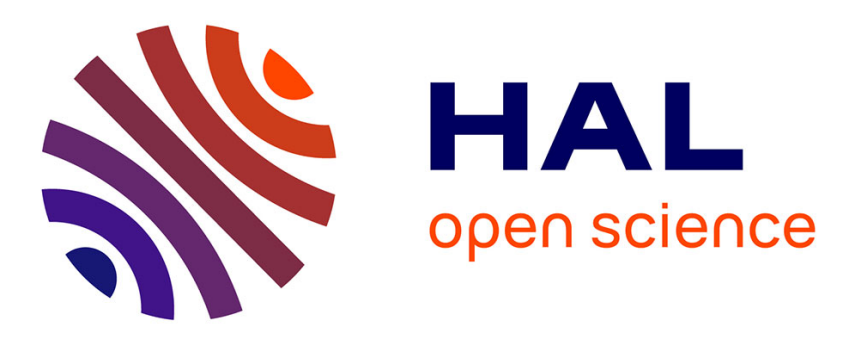

\title{
How to See Training Paths in Learning Management Systems?
}

Philippe Teutsch, Jean-François Bourdet

\section{To cite this version:}

Philippe Teutsch, Jean-François Bourdet. How to See Training Paths in Learning Management Systems?. 2010 10th IEEE International Conference on Advanced Learning Technologies, Jul 2010, Sousse, Tunisia. pp.349-351, 10.1109/ICALT.2010.98 . hal-01226463

\section{HAL Id: hal-01226463 \\ https://hal.science/hal-01226463}

Submitted on 27 Apr 2020

HAL is a multi-disciplinary open access archive for the deposit and dissemination of scientific research documents, whether they are published or not. The documents may come from teaching and research institutions in France or abroad, or from public or private research centers.
L'archive ouverte pluridisciplinaire HAL, est destinée au dépôt et à la diffusion de documents scientifiques de niveau recherche, publiés ou non, émanant des établissements d'enseignement et de recherche français ou étrangers, des laboratoires publics ou privés. 


\title{
How to See Training Paths in Learning Management Systems?
}

\author{
Philippe Teutsch, Jean-François Bourdet \\ LIUM, Laboratoire d'Informatique de l'Université du Maine \\ Le Mans, France \\ \{Philippe.Teutsch ; Jean-Francois.Bourdet\}@univ-lemans.fr
}

\begin{abstract}
This paper presents on-going research concerning the design of monitoring features for human-computer interfaces (HCI) for long distance training courses. The objective is to design visualization tools that facilitate the task of the on-line course teacher. The teacher needs to see the learning path and learners contributions in the Learning Management System (LMS). The paper successively presents the research issues related to computer design of such interfaces, a typology of different dimensions to be taken into account (scenario, participants, calendar) and a tool designed for on-line monitoring of individual paths inside a training course (CROISIÈRES). Perspectives concern a methodological framework for HCI design and evaluation in the context of supervisory control in distance course.
\end{abstract}

Keywords-component; Distance education, monitoring, human-computer interface, visualization tools.

\section{INTRODUCTION}

Distance education platforms create complex and highly dynamic systems where the on-line teacher faces difficulties to monitor the participants' learning activities. These difficulties are related to the position of distant working and to the lack of global perception of the individual situations. The tutors have to reconstitute for themselves the puzzle of learners' activities through the information that the environment provides them with. Thus, they need structured information about the learners' activities in order to give them relevant and effective help. The aim of the research is to aid teachers in distance training courses in gaining an understanding of their learners and becoming more aware of what is happening in the group they are responsible of [13]. Most researchers present the training curriculum as a process the teacher has to back up and regulate [8]. So, the tutoring task is in fact a monitoring activity of the learning process.

\section{TRAINING COURSES MONITORING ACTIVITY}

Usually, training device modeling concerns engineering, design [7], scenario scripting [8], re-engineering [4], or tracking actions on the system [5]. These models are formalized using appropriate languages. It is less common to try to describe the device in terms of its use by the tutor. Yet it is essential for the tutor to know the situation in which the learner is to respond to his solicitations, i.e. to contextualize the events to be considered.

\section{A. Learning Process Modeling}

The training model proposed by [17] organizes the learning situation of each learner in three stages of data: (1) the identity and the training context of the person (no significant evolution during the session); (2) the profile of the person, i.e. the disciplinary skills (level of knowledge rationally improving during the session), the control of the training device (experience to quickly acquire at the beginning of the session) and the "how to learn" skills (that can be partially improved during the session); (3) the personal path into the device. This path includes foreseen and actual training choices, declined in intermediate points and overall activity report, and the local situation, expressed in contributions to the proposed activities.

The learning process can therefore be seen as a set of data of various kinds, apparently independent but in fact inter-related. This data set is observed at different levels of details: global training pathway, recent period of learning activity or current phase of exercise for example.

\section{B. Pedagogical Monitoring Task Modeling}

The perception of learners' activity requires situating the individual activity according to the training device and the group's achievements. In order to do that, the tutor has to take an interest in the learners' productions, in the exchanges between learners, and in the group dynamics [12]. Nevertheless, the central task of the tutor is to observe each learner's learning path. The group is an element of the context, like the scenario or time constraints.

Learning Management Systems (LMS) usually keep a record of the students' activities in a distance course. LMS accumulate large logs of data of student activities and usually have built-in monitoring features that enable the instructors to view some statistical data such as the history of pages visited, the messages read or posted in discussions, marks achieves in quizzed, and so on [13]. This complex information is rarely used by teachers since it is predominantly in numerical or alphanumerical format, with a poor logical organization, and difficult to manage.

Usually, tutors become aware of the student's software interactions and corresponding skills acquisition, from three kinds of data: productions to assess, messages posted in forum or by email, and system notifications. They need rapid identification of the learner's situation; not only a record of the learner's activity on the device, but also the articulation of this current situation with the history of the last few sessions, including the complete learning journey, or paths and situations of the other learners.

\section{Pedagogical Monitoring HMI Needs}

LMS platforms allow access to the interactions between user and system, but rarely propose synthetic views to the 
coaching teacher [1][2]. This lack is a problem of designing and developing human-computer interfaces dedicated to the on-line tutor needs [14].

Conceptually, a tutoring interface depends on three principles linked to the tutor's perception of the learner's situation [17]: (1) Context of emergence. The tutor can access the emergency context of the solicitation, i.e. the activity page where the learner was at the moment of the solicitation (production, message or warning). (2) Articulation: for each learner, the tutor has to decide message priority; which messages, warnings or production to treat next. The answer can be in the story (recent or not) of the learner with the device. The tutor has to visualize the learner's work using a "zoom" on the learning situation. The levels of focus correspond to the levels of granularity of this situation. (3) Individual assessment: this is built according to the real journey and the solicitations coming from the learner and his activities.

\section{VIEWS ON THE TRAINING PATH}

Distance course design considers the learner as the centre of the device. The way to self-directed learning is therefore essential. In order to support the creation of such autonomy, it is necessary to provide tools adapted to the monitoring individualized learning paths.

\section{A. Visualization artifact and research methodology}

The problem of information visualization is to reduce a large volume of evidence but with low semantic value in a visual composition with high semantic value [15]. In the case of monitoring training, it is to allow both investigation and contextualization to "understand" learning situations. The information visualization seeks to visually represent abstract data in order to gain insight into the phenomena that emerge from these data [6]. The goal is to make discoveries, decisions, or find explanations. For example, the CourseVis system [14] uses 2D and 3D matrices to represent the contributions of each learner for the activities he has made: access to resources, success in quiz score, or participation in the forums.

Researches in information visualization (InfoVis) are studying ways of getting visual information from raw data [3] [10] and/or from combination of heterogeneous data [16]. Techniques generally apply a "projection" of data on a visualization space.

\section{B. Model}

We propose a theoretical framework identifying the various parameters involved in the definition of visualization interfaces. We then show that the combination of these parameters can lead to a set of distinct and complementary views that meet the initial tutors' needs.

The data for describing a training session are numerous, varied and multifaceted. They are both based on models of tasks required for the actors of the device (curriculum, scenario-based learning activities, task schedule), lists of users (students enrolled in training session) and corpora of users' contributions. We define a model of training device based on three dimensions.
- The Scenario dimension describes the structure of training course: what content, what tasks and what methods of participation are provided? The scenario highlights the structure of the device (activity, sequence, module ...).

- The Participants dimension concerns actors of the current session and the social environment of it. For each participant, beyond identity, it may be useful to know his expertise or his role in the group.

- The Calendar dimension highlights the importance of temporal perspective on the training session. It aims to quantify and plan expected time to work, but also reflect the actual rhythm of learning.

This typology provides a framework for the creation of views necessary for the tutor to perceive the situation of the learners he is responsible of. A view is built by "projection" of one of these dimensions to another dimension of reference. Here are some simple examples of possible projections between the axes Scenario, Participants and Calendar:

- The projection of a learner (axis Participant) over a period of the Calendar shows his/her time of participation in various activities on the period.

- The projection of a learner (axis Participant) on an activity (axis Scenario) shows the contributions of the learner in the activity concerned.

- The projection of an activity (axis Scenario) on the Calendar shows the expected time to perform the activity and therefore the workload expected.

\section{Implementation and experimentation}

We present an example of this model's implementation on CROISIÈRES, an on-line language learning system that offers a set of structured resources in order to reach a threshold level in French [9]. Several monitoring instruments are available: dashboards, individual assessments and paths, detailed views on contributions. The chronological view (Figure 1) presents a synthesis of the learner's journey (Principle 3, individual assessment). The time is divided into three periods: the past that represents the journey of the learner, the present that details recent learning activity, and the future that indicates the time available until the end of the course. The page shows three types of information: productions to assess, messages from learners, warning notifications generated by the system (the observation of the learner's work identifies long periods of inactivity, repeated failures in the same exercise, or excessive navigation between several modules). These different items can be related to each other (Principle 2, articulation). The tutor can access productions and the context of activity of the learner from each segment of the learning unit. (Principle 1, context of emergence).

The next stage of the development concerns the combination (rather than the juxtaposition) of views. The principle is that of a direct combination between the reference dimensions: scenario, participants, and calendar. 


\section{CONCLUSIONS}

Monitoring HCI in the domain of distance training course is the main focus of this paper. The perception of learning situations and monitoring activities are essential to teachers, who are responsible for the facilitation and regulation of a training course. But the traces associated with these activities are numerous and varied. Their simplified and individualized display is not suitable for tutors who need to have an overview of each situation.

The mode of combination of views proposed in this article aims to show the traces taken from an on-line training device. The technique seems original and fruitful, and offers a wide variety of perspectives, using a simple model. These proposals will lead to extensive usability tests, especially regarding their ability to facilitate the perception of individual situations within a group.

The instrumentation approach focuses on modeling the process of supervision in terms of situation assessment and decision making [11] and on software architecture for integrating tools to support supervision.

\section{REFERENCES}

[1] S. Bull and P. Gardner, "Highlighting Learning Across a Degree with an Independent Open Learner Model", in V. Dimitrova, R. Mizoguchi, B. du Boulay \& A. Graesser (eds), Artificial Intelligence in Education 2009, IOS Press, Amsterdam, pp. 275-282.

[2] S. Bull and J. Kay, "Metacognition and Open Learner Models", in I. Roll \& V. Aleven (eds), Proceedings of Workshop on Metacognition and Self-Regulated Learning in Educational Technologies, International Conference on Intelligent Tutoring Systems, 2008, pp. 7-20.

[3] S. Card, J. Mackinlay and B. Shneiderman, Readings in Information Visualization - Using Vision to Think, Morgan Kaufmann, 1999.

[4] C. Choquet and S. Iksal, "Modeling Tracks for the Model Driven Reengineering of a TEL System", Journal of Interactive Learning Research (JILR), Special Issue Usage Analysis in Learning Systems: Existing Approaches and Scientific Issues, Vol. $18 n^{\circ} 2$, 2007, pp. 161-184.

[5] D. Cram, D. Jouvin and A. Mille, "Visualisation interactive de traces et réflexivité : application à l'EIAH collaboratif synchrone eMédiathèque“, Revue STICEF, Vol 14, 2007, http://sticef.org
[6] JD. Fekete, "The InfoVis Toolkit", InfoVis'04, 10th IEEE Symposium on Information Visualization, 2004, pp. 167-174.

[7] S. George, "Contextualizing Discussions in Distance Learning Systems", Proceedings of the 4th IEEE International Conference on Advanced Learning Technologies (ICALT), Joensuu, Finland, 2004, pp. 226-230.

[8] V. Guéraud and JP. Pernin, "Developing pedagogical simulations: generic and specific authoring approaches", Proceedings of Artificial Intelligence and Education Conference (AIEd), Le Mans, France, 1999, pp. 699-701.

[9] O. Gueye, "Instrumentation des activités du tuteur en ligne : le cas de CROISIERES, dispositif de formation ouvertes et à distance en langues", Thèse de doctorat de l'Université du Maine, spécialité informatique, Le Mans, 2005.

[10] J. Heer, SK. Card and JA Landay, "Prefuse: a toolkit for interactive information visualization", CHI 2005, Human Factors in Computing Systems, Portland, 2005, pp. 421-430.

[11] JM. Hoc, Supervision et contrôle de processus: la cognition en situation dynamique, Presses Universitaires de Grenoble, Grenoble, 1996.

[12] Ch. Laperrousaz, "Le suivi individuel d'apprenants engagés dans une activité collective à distance - TACSI un environnement informatique support aux activités du tuteur", Thèse de doctorat de l'Université du Maine, spécialité informatique, Le Mans, 2006.

[13] R. Mazza and V. Dimitrova, "CourseVis: Externalising Student Information to facilitate Instructors in Distance learning", Proceedings of the conference Artificial Intelligence in Education, (AIEd), Sydney, Australia, IOS press, 2003, pp. 279-286.

[14] R. Mazza and V. Dimitrova, "CourseVis: A graphical student monitoring tool for supporting instructors in web-based distance courses", International Journal of Human-Computer Studies, Vol 65, Issue 2, 2007, pp. 125-139.

[15] B. Shneiderman, "The eyes have it: A task by data type taxonomy of information visualizations", Proc. IEEE Symposium on Visual Languages, Los Alamitos, CA, 1996, pp. 336-343.

[16] B. Shneiderman and C. Plaisant, Designing the User Interface, Strategies for Effective Human-Computer Interaction, Addison Wesley, 4ème edition, 2004, $672 \mathrm{p}$.

[17] Ph. Teutsch, JF. Bourdet, and O. Gueye, "Perception de la situation d'apprentissage par le tuteur en ligne", Proc. TICE'2004, Compiègne, France,2004, pp. 59-66.

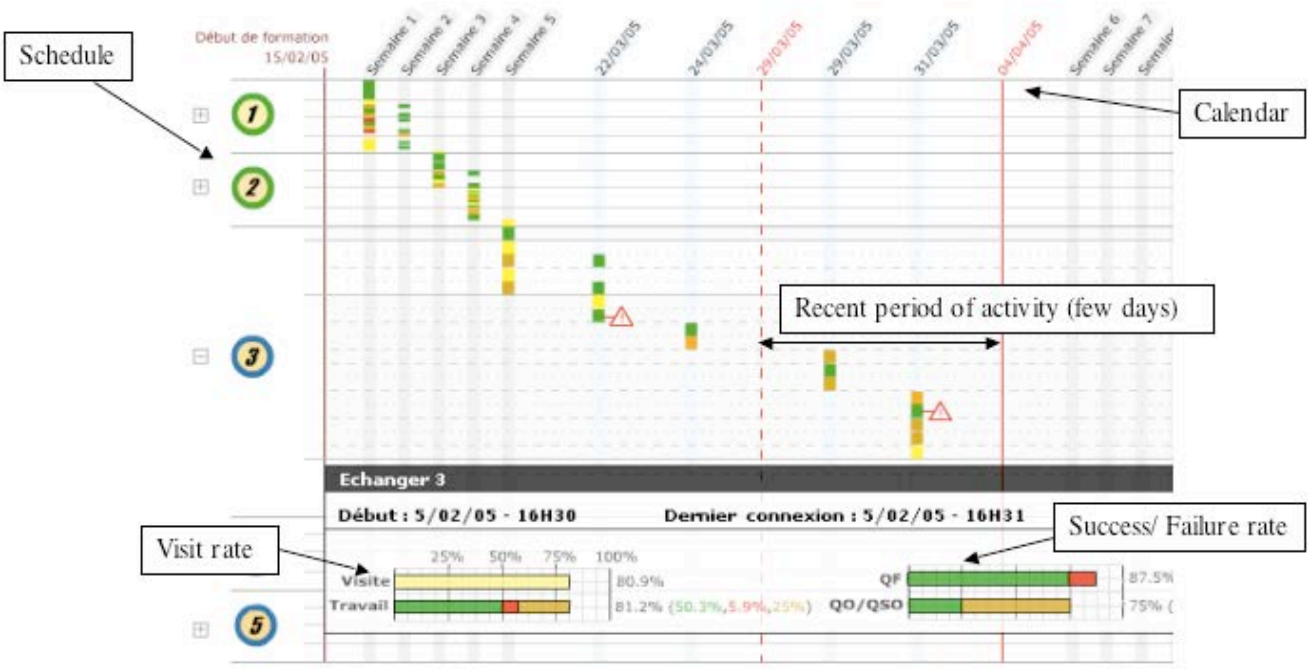

Figure 1. Project CROISIERES: overview of the learning path 